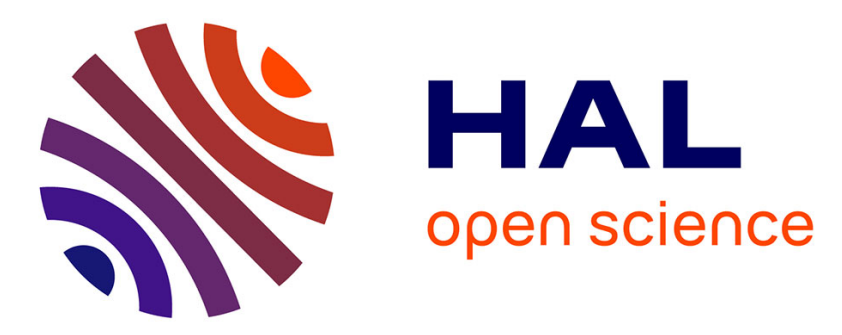

\title{
Structure-Properties Relationship in the Evaluation of Alginic Acid Functionality for Tableting
}

\author{
Rihab Benabbas, Noelia Sanchez-Ballester, Bernard Bataille, Laurent
}

Leclercq, Tahmer Sharkawi, Ian Soulairol

\section{- To cite this version:}

Rihab Benabbas, Noelia Sanchez-Ballester, Bernard Bataille, Laurent Leclercq, Tahmer Sharkawi, et al.. Structure-Properties Relationship in the Evaluation of Alginic Acid Functionality for Tableting. AAPS PharmSciTech, 2020, 21 (3), pp.2373 - 2378. 10.1208/s12249-020-1633-3 . hal-02903913

\section{HAL Id: hal-02903913 \\ https://hal.science/hal-02903913}

Submitted on 2 Dec 2020

HAL is a multi-disciplinary open access archive for the deposit and dissemination of scientific research documents, whether they are published or not. The documents may come from teaching and research institutions in France or abroad, or from public or private research centers.
L'archive ouverte pluridisciplinaire HAL, est destinée au dépôt et à la diffusion de documents scientifiques de niveau recherche, publiés ou non, émanant des établissements d'enseignement et de recherche français ou étrangers, des laboratoires publics ou privés. 


\title{
Structure-Properties Relationship in the Evaluation of Alginic Acid Functionality for Tableting
}

\author{
Rihab Benabbas,1 Noelia M. Sanchez-Ballester,1 Bernard Bataille,1 Laurent Leclercq,2 \\ Tahmer Sharkawi, 1 and Ian Soulairol $1,3,4$
}

Abstract. The aim of this study is to investigate the relationship between the structural, molecular, and particulate properties of alginic acid and its functional characteristics in direct compression (tabletability, compressibility, elasticity, deformation mechanism, and disintegration ability). Therefore, accurate characterization of two different batches of alginic acid was executed (X-ray powder diffraction, Fourier-transform infrared spectroscopy, thermogravimetric analysis, scanning electronic microscopy, ${ }_{1} \mathrm{H}$ nuclear magnetic resonance, size exclusion chromatography - multi angle light scattering, viscosimetry, carboxylic acid titration, powder flowability, true density, laser granulometry). Results showed that molecular weight seems to affect tablet properties and that the alginic acid with the lowest molecular weight provides the hardest tablets with the lowest elastic recovery. Furthermore, these results show the potential interest of exploiting alginic acid as filler excipient in tablet formulation. Finally, disintegration properties of tested materials were found to be close to that of commercial superdisintegrants (Glycolys ${ }^{\circledR}$ and Kollidon $\mathrm{Cl}$ ( ) but not correlated to their swelling force. It can be concluded, for the first time, that the determination of alginic acid molecular weight seems key for applications in direct compression and in particular for obtaining tablets with reproducible strength.

KEY WORDS: alginic acid; physicochemical characterization; direct compression; swelling force; disintegration.

\section{INTRODUCTION}

Tablets continue to be the most used drug delivery systems since many years ago. The mechanical properties, the disintegration, and dissolution characteristics of tablets are

\begin{abstract}
Abbreviations: $A A$, Alginic acid; $X R D$, X-ray diffraction; FTIR, Fourier-transform infrared spectroscopy; $T G A$, Thermogravimetric analysis; SEM, Scanning electronic microscopy; ${ }^{1} H$ NMR, Nuclear magnetic resonance; SEC/MALS, Size exclusion chromatography/ multi angle light scattering; $M$, D-mannuronic acid; $G$, L-guluronic acid; Lac, Lactose; $M C C$, Microcrystalline cellulose; $M g S t$, Magnesium stearate; Gly, Glycolys $® ;$ Kol, Kollidon $\mathrm{Cl}$.
\end{abstract}

it is still extensively used as binding and sustained release excipient for the preparation of oral dosage forms (6-8). The alginate concentration in the tablet formulation, the polymer chain composition (mannuronic acid (M) vs. guluronic acid (G) ratio), the viscosity, and the molecular weight $(7,9,10)$ are directly related to the tableting properties and to the drug release profile. dependent of their different ingredients. Thus, to achieve the desired therapeutic performance, the understanding of the excipient's physicochemical properties at molecular and particulate level is a fundamental step that must to be handled with care before tablet processing. Currently, severa natural and synthetic excipients presenting various functionalities (fillers, binders, disintegrants, and lubricants) are available in the pharmaceutical market. However, the use of natural materials is the main objective of many tablet manufacturers dealing with the development of new pharmaceutical formula with enhanced functional properties.

Alginic acid (AA) and sodium alginate are well-known natural linear polymers, obtained from various species of brown seaweeds (Laminaria hyperborea, Ascophyllum nodosum, and Macrocystis pyrifera) $(1,2)$ and also extracellularlv nroduced bv Pseudomonas aeruginosa and Azotohacter

vinelandii (3). Their distinct uses in the medical field are related to their biocompatibility, biodegradability, and low toxicity. Furthermore, the ability of alginates to form high viscous acid gels and ionotropic gels (4) makes from them excipients of interest.

Although sodium alginate has been largely studied and investigated for different biomedical and pharmaceutical applications (gelation, dispersing, and thickener agent (5)),

Distilled water was used for the swelling and disintegration experiments, and ultra-pure water was used for titration and viscosity measurements.

\section{METHODS}

Physicochemical Characterization 
Interestingly, while these factors have been largely studied for sodium alginate, no many studies are found for alginic acid (AA). The latter is used as a binding agent and as disintegrant in tablets designed for immediate drug release (11-13). It possesses high sorption capacity and poor solubility in water, and it disintegrates by swelling or wicking action (14). However, to date, no study has evaluated the relationship between the structure properties and the tableting behavior of pure alginic acid in direct compression.

Thus, in an attempt to search for an excipient presenting good compactibility, binding property, and disintegration ability, suitable for tablet formulation, the aim of this study was to characterize commercial alginic acid powders and to correlate the physicochemical properties of this material to its mechanical behavior. The compaction study was realized by using a rotary tablet press simulator Styl'one Evolution for direct compression, since the pharmaceutical industry always requires innovation in this field of application.

For this purpose, a full physicochemical characterization of two different batches of alginic acid was performed using several analytical techniques in order to understand the structure-functionality relationship. Compaction behavior was examined by the study of the tabletability, compressibility, elastic recovery, and deformation mechanism under different compaction pressures. Finally, the functionality of alginic acid as a disintegrating agent was tested by formulating it with common fillers available on the market (micro-

crystalline cellulose and lactose) and was compared to other commercial superdisintegrants (Glycolys ${ }^{\circledR}$ and Kollidon CL®).

\section{MATERIALS AND METHODS}

\section{Materials}

Two batches of alginic acid were studied for their physicochemical properties and comparative functionalities: (AA1 Batch number: SLBL2988V and AA2 Batch number: SLBT2973) supplied from Sigma-Aldrich, Germany. Lactose (Spray Dried $\alpha$-lactose monohydrate) (Excipress SD2®, Armor Pharma, France) and microcrystalline cellulose (Vivapur $200 \AA$, JRS Pharma, USA) were used as directly compressible filler-binder excipients. Magnesium stearate (Barlocher-Wiga Pharma GmbH, Germany) was used as lubricant.

Glycolys ${ }^{\circledR}$ (Roquette Frères, France) and Kollidon $\mathrm{Cl} \circledast$ (BASF, Germany) were used as commercial superdisintegrants for comparison with alginic acid.

Other reagents used such as hydrochloric acid 37\% (PanReac, Spain), sodium chloride, sodium hydroxide, an deuterium oxide were supplied from Sigma-Aldrich (Germany).

\section{$X$-Ray Diffraction $(X R D)$}

The crystalline or amorphous character of the alginic acid samples was studied using a Bruker D8 Advance diffractometer and the monochromatic $\mathrm{Cu} K \alpha 1$ radiation $(\lambda \alpha=1.5406 \AA, 40 \mathrm{kV}$ and $40 \mathrm{~mA})$. It was recorded with $0.02^{\circ}$ (2) steps over the $10-80^{\circ} 2$ angular range with $0.1 \mathrm{~s}$ counting time per step using LINXEYE detector 1D.

Fourier-Transform Infrared Spectroscopy (FTIR)

Infrared spectroscopy was recorded from 4000 to $500 \mathrm{~cm}^{-1}$ using a FT-IR Nexus spectrometer DuraSamplIR II equipped with an in-compartment diamond ATR accessory. The IR data were treated and stored using Spectrum software OMNIC (5.0) (Thermo Fisher Scientific, USA).

\section{Thermal Gravimetric Analysis (TGA)}

Composition and thermal behavior were evaluated on 10 to $20 \mathrm{mg}$ samples weighed in a ceramic pan, by thermal gravimetric analysis (TGA, STA 6000, Perkin Elmer, USA) from 30 to $600^{\circ} \mathrm{C}$ under airflow.

Alginic Acid Titration

The carboxylic acid content of both alginic acids was determined by acid-base titration according to the method described in the European Pharmacopoeia (15).

A known excess of $0.1-\mathrm{M} \mathrm{NaOH}(25 \mathrm{ml})$ was added to a suspension of $250 \mathrm{mg}$ of alginic acid in water, and the mixture

was stirred until all the alginate was dissolved. The unreacted base was back-titrated with $0.1-\mathrm{M} \mathrm{HCl}$ using phenolphthalein as indicator. The determination was done in triplicate.

Each $1 \mathrm{ml}$ of $0.1-\mathrm{M} \mathrm{NaOH}$ used for the neutralization of alginic acid is equivalent to $4.502 \mathrm{mg}$ of carboxyl groups $(-\mathrm{COOH})$.

\section{Molecular Weight Determination}

Two methods were applied to investigate the molecular weight of alginic acid: Viscosity Average Molecular Weight $\left(M_{\eta}\right)$. Alginic acid average molecular weight was determined from viscosity measurements using the rollerball viscometer Lovis $2000 \mathrm{M} / \mathrm{ME}$ (Graz, Austria).

Five different concentrations of each batch of alginic acid were dissolved in $0.1-\mathrm{M} \mathrm{NaCl}$ solution $(0.001,0.002,0.003$, 0.004 , and $0.005 \mathrm{~g} / \mathrm{ml}$ ) after $100 \%$ neutralization of the carboxylate groups by first adding 1-M NaOH.

The curve of reduced viscosity versus concentrations allowed the determination of the intrinsic viscosity $[\eta]$ for each sample by extrapolation to zero the polymer concentration. The intrinsic viscosity is correlated to the molecular 
weight of linear polymers according to the Mark-HouwinkSakurada equation (Eq.1) (16):

$$
[\eta]=\mathrm{k} M_{\eta}^{\alpha}
$$

where $[\eta]$ is the intrinsic viscosity, $M_{\eta}$ is the average molecular weight, and the constants $K$ and $\alpha$ depend on the solvent and polymer type. For this study, $\mathrm{K}=7.3 \times 10^{-3}$ and $\alpha=0.92$ as determined by Martinsen (17) for alginates from Macrocystis pyrifera were used to calculate the average molecular weight in $0.1-\mathrm{M} \mathrm{NaCl}$.

Size Exclusion Chromatography - Multi Angle Light Scattering (SEC-MALS). The SEC-MALS experiments were performed on a Thermo Scientific Ultimate 3000 module equipped with a OHpak SBG Shodex column guard $(50 \times$ $6 \mathrm{~mm})$ and one SB-805-HQ Shodex columns $(300 \times 8 \mathrm{~mm})$ connected in series in association with a miniDawn Treos three-angle laser light scattering detector (41.5, 90, and $138.5^{\circ}$ ) having a 658 -nm laser (from Wyatt Technology Corp., Santa Barbara, CA, USA) and with a RID-6A refractive index monitor (from Shimadzu Corp., Kyoto, Japan) at a thermostated temperature of $35^{\circ} \mathrm{C}$. The eluent used was composed of a mixture of $150 \times 10^{-3} \mathrm{M}$ phosphate buffer and $1-\mathrm{M} \mathrm{NaCl}$ at $\mathrm{pH}=7.4$. The eluent was filtered using Durapore

membrane filters of $0.1-\mu \mathrm{m}$ cut-off. Incremental refractive index $(\mathrm{dn} / \mathrm{dc})$ value of 0.15 was used, as found in the literature $(17,18)$. The polymer samples $(100-\mu \mathrm{L}$ injection volume at a concentration of 2 g. $\mathrm{L}^{-1}$ ) were eluted at a 1-mL.min ${ }^{-1}$ flow rate. The data were analyzed using the Astra software (v6.1.1.17, from Wyatt Technology Corp.).

\section{Uronic Acids Composition}

The uronic acid compositions of both batches were characterized by ${ }^{1} \mathrm{H}$ NMR (nuclear magnetic resonance). The samples were prepared as described previously by Grasdalen (19).

One gram of alginic acid was fully neutralized by titration with 1-M NaOH. The obtained solution was subjected to partial hydrolysis by treating them successively with two acidic solutions ( $\mathrm{pH} 5.6$ and $\mathrm{pH} \mathrm{3.8)}$ at $90^{\circ} \mathrm{C}$ for $60 \mathrm{~min}$ and $45 \mathrm{~min}$, respectively.

Finally, the $\mathrm{pH}$ of the solution was adjusted to 6.8-7. Then, the sample was lyophilized, and $11 \mathrm{mg}$ of the hydrolyzed alginate were dissolved in $580 \mu \mathrm{L}$ of $\mathrm{D}_{2} \mathrm{O}$.

Analyzes were carried out on a $400 \mathrm{MHz}$ Bruker Avance III HD spectrometer equipped with a BBOF (broadband) probe. The ${ }^{1} \mathrm{H}$ spectrum was recorded at $75^{\circ} \mathrm{C}$ with a $\mathrm{TD}=$ $128 \mathrm{~K}$, a pulse delay of $4 \mathrm{~s}$, and a scan number of 256 . The data was processed by the software Topspin 3.5 Pl6 with a

$\mathrm{LB}=0.1$ and a $\mathrm{SI}=64 \mathrm{k}$. Further experimental details are clarified in Supplementary Data (Supplemental 1).

\section{True Density}

True density of the powders (AA1, AA2, lactose) was measured using a helium pycnometer 1305 (Micromeritics,

\section{Compaction Study}

\section{Tabletability}

Four hundred milligrams of pure tablets of each batch were compacted under different compaction pressures $(100$, 200 , and $300 \mathrm{MPa}$ ) using a rotary tablet press simulator Styl'one Evolution (Medelpharm, France). Flat punches of 11.28-mm diameter were used for the compaction study, and
USA), and the required mass of powder for each measurement was about $3 \mathrm{~g}$. Measurements were done in triplicate for each sample.

The true density of MCC was calculated from compaction data (tablet density and compaction pressure) according to the study realized by Sun C (20). As true density for MCC was found to be overestimated due to limitations of the helium pycnometer.

\section{Particle Size Distribution}

The particle size distribution of the dry powders was determined by laser diffraction (Mastersizer 2.18; Malvern Instruments Ltd.). Each measure was performed at least in triplicate, and the median particle diameter was used to express the particle size of alginic acid powders.

\section{Tapped and Bulk Density}

Tapped $(\rho \mathrm{T})$ and bulk density $(\rho \mathrm{B})$ were measured by following the method described in the European Pharmacopoeia (21). Their determination allows to calculate Carr's index $(\mathrm{C})$ and Hausner ratio $(\mathrm{H})$ according to Eqs. (2) and (3), respectively. These two parameters expressed the

flowability of the tested powders.

$C=100 *(1-\rho B / \rho T)$

$H=\rho B / \rho T$

\section{Scanning Electronic Microscopy}

Particles morphology was investigated by scanning electron microscopy (Hitachi $4800 \mathrm{~S}$ ) after platinum sputtering under vacuum before observation.

\section{Functional Characterization}

Swelling Force

Swelling force measurements were performed using a prototype equipped with a force sensor, ADAM PGL 2002 balance as described previously by Chaheen (22). The acauisition of data was carried out at the rate of one measurement per second using a bidirectional RS-232 interface. The software used to collect the data was an ADAM DU V1.11.27.0. The data were reprocessed using Excel® software. All measurements were performed in distilled water. For each sample, three tests were performed, and results are presented as the mean value with standard deviation.

outside of the matrix, $\mathrm{Cl}$ is the crown depth of the lower punch, and $\mathrm{Cu}$ is the crown depth of the upper punch.

\section{Heckel and Walker Modeling}

For Heckel modeling, three tablets compacted of the two pure alginic acid materials, at different compaction pressures 100,200 , and $300 \mathrm{MPa}$, were used. They presented a constant mass of $400 \mathrm{mg}$. True densities $(\rho)$ measured previously with 
the speed rate was of $9.5 \mathrm{~mm} / \mathrm{s}$.

Tablet thickness, diameter, and hardness were measured using a Sotax Multitest 50FT (Sotax AG, Switzerland) Measurements were carried out on 10 tablets per compaction point, and results were expressed as the mean value standard deviation.

The diametric tensile strength (TS) was calculated from the crushing force using the following equation (Eq. (4)):

$$
T s={ }^{2} \mathrm{~F} / \pi \mathrm{Dh}
$$

where $F$ is the diametric force necessary to break th cylindrical compact, $D$ the diameter of the compact, and $h$ its thickness, and its value accurately expresses the powder tabletability.

\section{Compressibility}

Compressibility of alginic acid was evaluated by the measurement of tablet porosity according to Eq. (5):

$\varepsilon=1-\rho r$

In which, the relative porosity $(\rho r)$ is calculated according to Eqs. (6) and (7):

$\rho r=\rho T a / \rho T r$

$\rho r=m T / \pi R 2 h T \rho T r$

where $\rho T a$ is the density of tablet, $\rho T r$ is true density, $R$ is the radius of tablet, $h T$ is its height, and $m T$ is its mass.

\section{Elastic Recovery}

The elastic recovery (ER) of each powder was calculated using the Analis ${ }^{\circledR}$ software. It corresponds to the evolution of the tablet thickness between the compression peak and the measurement of the thickness outside the matrix. This evolution is characterized by percentage (\%). The measurement was done according to the following equation (Eq. (8)):

$E R=\frac{T h-(D+C l+C u)}{(D+C l+C u)} \cdot 100$

where $D$ is the distance between the punches during the compression peak, Th is the measured thickness of the tablet the helium pycnometer were used to calculate Heckel mean yield pressures (Py) which are given by the inverse values of the slope of the following equation (Eq. (9)):

$\operatorname{Ln}\left(\frac{1}{1-D}\right)=\mathrm{K} P+\mathrm{A}$

where $K$ is the slope of the linear part of the plot (with the best $R^{2}$ fit) and $A$ is the $Y$ axis intercept with the linear part of the Heckel plot. Hersey and Rees (23) defined that Py values can be used to characterize the deformation mechanism of materials. For them, the low value of Py reflects the plastic deformation of a hard ductile powder, while Py high value reflects a fragmentary deformation of a brittle material under compaction force.

For Walker modeling, true density is also used to determine the evolution of the powder relative volume with the increase of the compaction pressure (24), and Walker defines « W » as the compressibility coefficient which represents the slope of the following (Eq. 10):

$100 V=-W * \log (p)+\mathrm{C}$

where $V$ is the relative volume, $P$ is the compaction pressure and the constant $\mathrm{C}$. The compressibility coefficient « W » indicates a measure of the irreversible compressibility of the

compact, the higher is the $W$ value, the better is the compressibility of the powder. This model is more robust and more repeatable than Heckel but less accurate.

For this study, lactose and microcrystalline cellulose were also used as reference materials to interpret the deformation mechanism of alginic acid.

\section{Formulations}

Different formulations were tested using $5 \%$ of alginic acid with each one of the following direct compression diluents: lactose (at $94.5 \%$ with $0.5 \%$ of $\mathrm{MgSt}$ ) and $\mathrm{MCC}$ (at $95 \%$ without lubrification).

The tablets produced with Styl'one Evolution simulator are flat and round, presenting a constant mass of $400 \mathrm{mg}$. The tablets were obtained at different compression pressures 100 , 200 , and $300 \mathrm{MPa}$, respectively, and a speed rate of $9.5 \mathrm{~mm} / \mathrm{s}$.

The hardness of ten tablets of each formulation was measured per compaction point, and results were expressed as the mean value \pm standard deviation.

The disintegration test was performed according to the European Pharmacopoeia guidelines (25) using a disintegration apparatus (ERWEKA ZT-31, Heusenstamm, Germany). Six tablets of each formulation were tested simultaneously, and the results expressed as the mean value \pm standard 
deviation. The end point was achieved when no residues were present on the bottom of the test basket as described in the European Pharmacopoeia (25)

\section{RESULTS AND DISCUSSION}

\section{Physicochemical Characterization}

\section{Structural Analysis}

The examination of X-ray diffraction patterns ( $p$ XRD) of alginic acid (AA1 and AA2) powders showed the appearance of two diffraction peaks at 14.22 and $20.91^{\circ}$ for both batches followed by a broad peak. The obtained $p$ XRD present very poor diffraction patterns, consistent with their amorphous structure but also presenting some extend higher structural order (Supplemental 2). These results are in agreement with several studies reported on the atomic structure of alginic acid (26).

According to Ikeda and Takemura, the two diffraction peaks observed at $14.22^{\circ}$ and $20.91^{\circ}$ are related to the presence of homopolymeric blocks (MM or GG) in the molecular chain of alginic acid (27).

Infrared spectroscopy was realized in order to identify the functional groups of alginic acid (Supplemental 3). A band was observed at about $1724 \mathrm{~cm}^{-1}$ assigned to the carboxylic acid stretching vibrations $(-\mathrm{COOH})$. Another

broad peak was found at $3396 \mathrm{~cm}^{-1}$ corresponding to the hydroxyl groups stretching vibrations $(-\mathrm{OH})$ in both spectrum. These observations are in agreement with previously reported literature $(12,28)$.

Thermogravimetric analysis carried out under air flow allowed the study of thermal behavior of both alginic acid batches. This analysis was also employed to estimate the ash and water content of each sample and their degradation profile (Supplemental 4).

The first thermal event $\left(50-130^{\circ} \mathrm{C}\right)$ corresponds to wate loss, which is similar for both batches of alginic acids about ( 8 to $9 \%$ of weight loss). The next thermal event in the temperature range of $180-250^{\circ} \mathrm{C}$ with a loss of about (about $34 \%$ ) is related to the degradation and the destruction of glycosidic bonds. The last thermal event in the temperature range of $250-600^{\circ} \mathrm{C}$ (about $52 \%$ ) corresponds to the further decomposition of the osidic residues. At 500 to $540^{\circ} \mathrm{C}$, both batches of alginic acid are degraded completely which shows the absence of mineral residues. These results are in agreement with those obtained by Soares (29).

\section{Alginic Acids Titration}

From titration results, it was found that AA2 possesses a carboxylic acid content of $25.52 \pm 0.18 \%$ slightly higher than that of AA1 $24.16 \pm 0.21 \%$, and this difference can be considered not significant; therefore, it is concluded that both

acids have similar acidity levels and degree of ionization.

The degree of carboxylic acid substitution is one of the principal parameters that govern the swelling of alginic acid. It favors polymer hydration, by ionizing the carboxylic groups $\left(-\mathrm{COO}^{-}\right)$in distilled water $(\mathrm{pH}>\mathrm{pKa}$ of alginic acid (3.4 3.6)), electrostatic repulsions will then occur between the ionized groups, and this will generate the swelling of alginic acid.

\section{Average Molecular Weight Determination}

Average molecular weights estimated by viscosimetry $\left(\mathrm{M}_{\eta}\right)$ (Supplemental 5) and size exclusion chromatography $\left(M_{w}\right)$ (Supplemental 6) were in agreement with each other as presented in Table I.

The determination of the molecular weight showed a difference between the two tested materials, and the mean average molecular weight obtained from the two methods is about $19,821 \mathrm{~g} / \mathrm{mol}$ for AA2, whereas that of AA1 is about $10,407 \mathrm{~g} / \mathrm{mol}$. That implies an average chain length of approximately 113 residues for AA2 and of about 59 residues for AA1. These results are close to that found by De Ramos for alginates obtained from Macrocystis pyrifera (30). Polydispersity index calculated from SEC/MALS results was found to be close to 1 for both batches (1.54 and 1.52 for AA1 and AA2, respectively), which means that within each polymer, the lengths of macromolecular chains are almost identical (31).

Uronic Acids Composition

Uronic acids composition from ${ }^{1} \mathrm{H}$ NMR results (Supplemental 7 and 8) was found to be close for both hatches and similar to that nhtained hy De Ramos (30) The details are shown in Table II.

It was found that AA1 has slightly higher $\mathrm{M} / \mathrm{G}$ ratio than AA2 sample. That could make AA1 fairly more flexible and more prone to deformation under compaction pressure than AA2 since $\mathrm{G}$ residues are known to be stronger and more resistant structures. However, both samples are elastic materials because of their richness on mannuronic acid homopolymers (MM). They both yielded $\eta$ parameter confined between 0 and 1 which indicates a block distribution of the uronic acids along their chains (19).

It can be concluded that there is not significant structura and chemical difference between the two batches of alginic acid from XRD, FTIR, and TGA results. The difference in uronic residues composition is also negligible. So, these physicochemical parameters will be excluded during the evaluation of the compaction study. On the other hand, the only difference that was observed and that will be considered for the functional study is the difference in their molecular weights.

\section{Particulate Analysis}

True densities measured seem to be comparable for both batches: $1.632 \pm 0.003$ and $1.608 \pm 0.004$ for AA1 and AA2,

Table I. Average Molecular Weight of AA1 and AA2

\begin{tabular}{lll}
\hline & Viscosimetry $M_{\eta}(\mathrm{g} / \mathrm{mol})$ & SEC/MALS $_{\mathrm{w}}(\mathrm{g} / \mathrm{mol})$ \\
\hline AA1 & $10,464 \pm 663$ & $10,350 \pm 300$ \\
AA2 & $21,191 \pm 454$ & $18,450 \pm 550$ \\
\hline
\end{tabular}

Table II. Chemical Composition of Alginic Acid Samples Obtained by ${ }^{1} \mathrm{H}$ NMR Analysis

\begin{tabular}{lllllllll}
\hline Sample & F G & F M & F GG & F GM/MG & F MM & $\eta$ & NG & M/G \\
\hline AA1 & $0.41 \pm 0.01$ & $0.59 \pm 0.01$ & $0.29 \pm 0.01$ & $0.11 \pm 0.03$ & $0.48 \pm 0.04$ & $0.47 \pm 0.11$ & $3.75 \pm 0.65$ & $1.45 \pm 0.08$ \\
AA2 & $0.43 \pm 0.01$ & $0.57 \pm 0.01$ & $0.32 \pm 0.01$ & $0.11 \pm 0.02$ & $0.46 \pm 0.03$ & $0.46 \pm 0.08$ & $3.99 \pm 0.73$ & $1.33 \pm 0.05$ \\
\hline
\end{tabular}

F G/F M, guluronic and mannuronic acid fractions; F GG /F MM /F GM, fractions of dyads sequences; $\eta$, parameter that describes the alternation of $\mathrm{M}$ and $\mathrm{G}$ groups; $\mathrm{NG}$, average number of $\mathrm{G}$ unit in $\mathrm{G}-\mathrm{blocs} ; \mathrm{M} / \mathrm{G}$, mannuronic/guluronic acid ratio 
respectively. This physical parameter has an impact on the flowability, the compressibility, and the deformation mechanism of each powder under compression pressure.

Powders particle sizes were determined using laser diffraction. The median particle diameters are between $67.07( \pm 2.60)$ and $69.85( \pm 3.25) \mu \mathrm{m}$ for the two powders tested (Supplemental 9). Previously reported research had demonstrated that small particle size leads to poor flowability but increases tablet mechanical strength as small particles possess more surface area exposed for particle bonding (32)

Carr's index and Hausner's ratio were measured from results of tapped $(0.74 \mathrm{~g} / \mathrm{ml}$ for both batches) and bulk densities $(0.52 \mathrm{~g} / \mathrm{ml}$ for AA1 and $0.53 \mathrm{~g} / \mathrm{ml}$ for AA2). Both batches were found to present a very poor flowability with Carr's index of 30.07 for AA1 and 29.01 for AA2 and Hausner's ratio of 1.43 for AA1 and 1.41 for AA2. Thi observation is mainly related to their small particle size. Tha represents a problematic for the utilization of these powders as filler in direct compression.

Figure 1 shows the scanning electron images of the studied materials at different magnifications. Both batche present particles with irregular morphologies and dense surfaces without any obvious porosity. AA2 presented particles that seem to have rougher surfaces, slightly large sizes, and more heterogeneous morphologies with an abundance of elongated-shaped particles. Contrary to AA1, which batch is composed of particles with predominately granula shape, more homogeneous particle forms distribution and

smoother surface.

That difference could be due to two factors: (i) the molecular arrangement of the polymer chain which has a further impact on the particle shape and size and/or (ii) could be related to the operation conditions of the powder manufacturing process. Therefore, the small size of the particles and their irregular shapes are the two main parameters that explain the poor flowability of these powders (33).

\section{Functional Characterization}

\section{Swelling Force}

Figure 2 shows the swelling force evolution profile in distilled water of the two batches tested as function of time.

Both of them swell in water, but AA2 reached a swelling force value at equilibrium phase, almost three times higher than that of AA1.

In distilled water ( $\mathrm{pH}$ 5.5), the carboxyl groups of alginic acid are ionized as its pka value is in the range of 3.4-3.6. Therefore, an electrostatic repulsion force is then developed between the ionized acid groups $\left(\mathrm{COO}^{-}\right)$which generates the swelling of the polymer in water. The hydrogel formed swells at a higher scale when the repulsion force created is higher.

In this study, it was not found a significant difference in the carboxylic acid proportion between the two batches. So, the difference observed in the swelling force is not attributed to the carboxylic acid content but rather related to the difference in the molecular weight. As AA2 possesses more uronic acid repeating units, it presented a tendency to hydrate better and to absorb more water than AA1 whose molecula chain is shorter, thus creating a greater swelling force. Moreover, AA2 possesses little higher GG segments in its molecular chain which is known to favor the formation of stronger gel upon hydration by creating more interactions between molecules $(10,34)$.

\section{Pure Tablets}

Tabletability

Tabletability is the capacity of a powder to be transformed into a tablet of specified strength under the effect of compaction pressure (35)

The tableting behavior of these two excipients was evaluated and represented by a plot of tensile strength versu compaction pressure in Fig. 3a. The tensile strength of these materials has been shown to be compaction pressure dependent and confined between 0.6 and $2.5 \mathrm{~N} / \mathrm{mm}^{2}$.

AA1 provided the hardest tablets for all compaction

forces; on the other hand, hard enough tablets could not be formed from AA2 at 100-MPa compaction force. At 200 and $300 \mathrm{MPa}$, tablets were manufactured but with lower hardness than those obtained for AA1.

Interestingly, the tablet hardness obtained for pure AA1 makes it a good candidate to be used as filler in the formulation of pharmaceutical tablets in addition to its disintegration ability.

\section{Compressibility}

Compressibility is the ability of a material to undergo a reduction in volume as a result of an applied pressure (35). The compressibility of the two alginic acid batches is represented by a plot showing the reduction of tablet porosity with increasing compaction pressure (Fig. $3 b$ )

AA1 tablets presented the lowest porosity at different compaction pressures which explains the higher ability of AA1 to form hard cohesive tablets. On the other hand, AA2 formed more porous tablets which leads to a decrease of their hardness as previously described.

As both batches presented different particles surface shape, the difference in their compressibility could be 

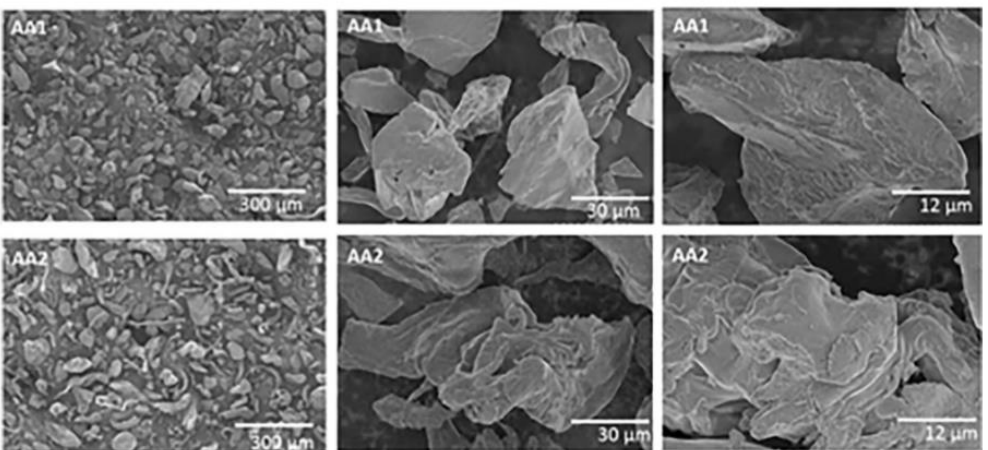

Fig. 1. SEM images of AA1 and AA2

attributed to the particle rearrangement during packing and compaction of the powders. This was confirmed by examining the tablet surface of the two batches. As Fig. 4 shows, AA1 particles are better arranged and bound together compared to AA2 particles.

On the other hand, the difference in compressibility could evenly be related to a difference in the powder elastic energy released after compaction from the two samples. This powder elastic energy is directly related to the tablet elastic

recovery which will be evaluated subsequently.

\section{Elastic Recovery}

The elasticity of each sample was determined by measuring the evolution of the elastic recovery as a function of the compressive force (Fig. 3c). It was found that AA2 forms more elastic tablets which explain the lowest hardness and the highest porosity of tablets obtained for AA2 powder. That could be related to the higher molecular weight of AA2 compared to AA1. During powder manufacturing, alginic acid presenting lower molecular weight (AA1) originate more organized structures yielding particles which deform more easily under stress condition and therefore forming harder tablets. Furthermore, the higher molecular weight of AA2 and its slightly higher content in GG residues might lead to greater intramolecular hydrogen bonding formation, thereby limiting chains mobility during compression which could explains the lower compactibility and the higher elastic recovery of AA2 tablets.

These results are comparable to those obtained by Schmid and Picker-Freyer for sodium alginates (7). In that work, it was found that sodium alginate presenting higher degree of polymerization gave tablets which deformed more elastically than the sodium alginate with lower degree of polymerization.

Along the same lines, a study conducted on different chitosan samples with different degree of acetylation has reported that the chitosan possessing the lowest molecular weight presented higher and easier deformation during compression and formed tablets which exhibited higher crushing forces (36). However, microcrystalline cellulose and gelatin $(37,38)$ were found to provide harder tablets when increasing their molecular weight. Hence, it can be deduced that the chemical nature of the polymer and its molecula composition have a great influence on its particle deformation (elastic, brittle, or plastic) and thus its mechanical behavior on compression.

\section{Heckel and Walker Modeling}

Heckel and Walker modeling were applied to compare the deformation mechanism of each material with two references: lactose (True density of $1.54 \mathrm{~g} / \mathrm{cm}^{3}$ ) and MCC (true density of $1.47 \mathrm{~g} / \mathrm{cm}^{3}$ ) that are known as brittle and

plastic materials, respectively. Figure 5 shows the evolution of the $\mathrm{W}$ and Py plots as function of compaction pressure.

Both alginic acid materials presented similar behaviors under compaction pressure. Heckel plots obtained for all materials were slightly influenced by the compaction pressure applied. Py values of both alginic acids at $200 \mathrm{MPa}$ (109.7 MPa and 103.2 MPa for AA1 and AA2, respectively) are lower than that of lactose and higher than that of MCC. They are closer to lactose than to MCC which means that they can be considered more brittle than ductile materials.

For Walker modeling, MCC presented the higher W values, and lactose exhibited the lower $\mathrm{W}$ values at high compaction pressures (200 and $300 \mathrm{MPa})$. Alginic acids showed intermediate results with W values closer to lactose's values (W AA1, 43.2, and W AA2, 49.6, at $200 \mathrm{MPa}$ ).

These results reveal a brittle behavior of alginic acid, with properties slightly more ductile than lactose under compaction pressure.

So, it can be concluded that alginic acid possesses a deformation mechanism close to that of lactose, generally
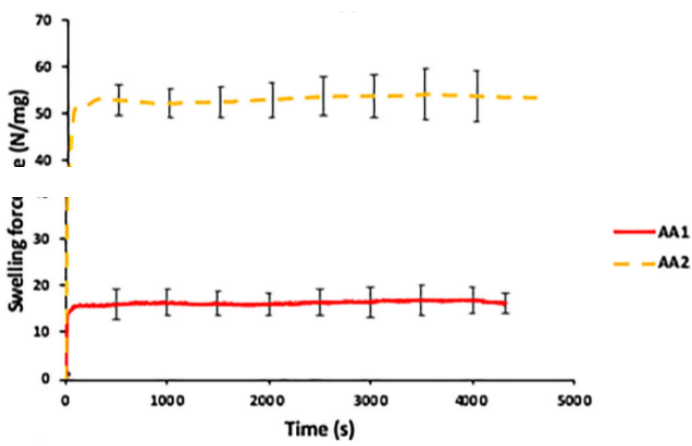

Fig. 2. Curves of swelling force as a function of time for AA1 and AA2 

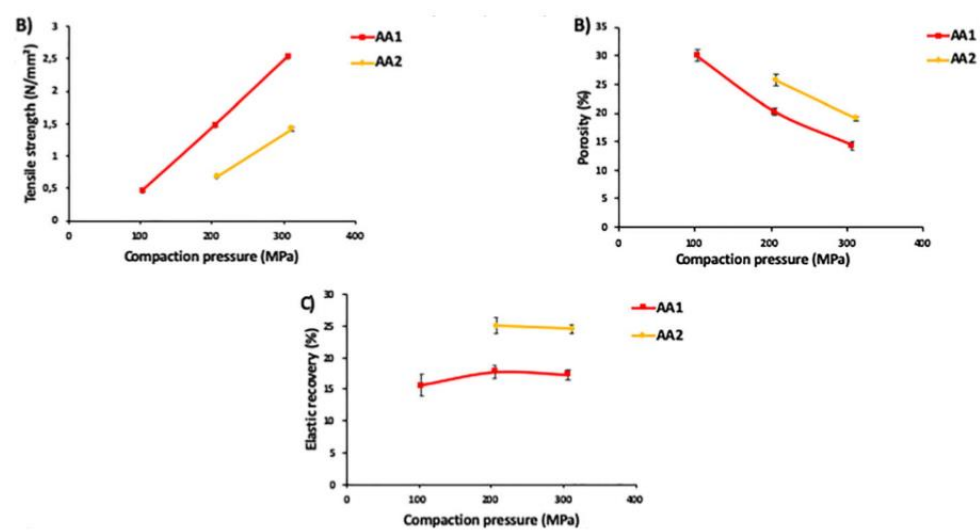

Fig. 3. Curves of tensile strength (a), porosity (b), and elastic recovery (c) as function of compaction pressure for pure $\mathrm{AA} 1$ and $\mathrm{AA} 2$ tablets

described as fragmentary. On the other hand, it presents also a slight elastic behavior which occurs after decompression as was observed from elastic recovery results.

\section{Formulations}

Each alginic acid was formulated with MCC and lactose

to test the disintegrant functionality of this material. The effect of the addition of this excipient was evaluated on tablet's hardness and disintegration time. This part has allowed to evaluate the mechanical effect of alginic acid added at low content $(5 \%)$ in tablet formulation and to compare its disintegration ability with other superdisintegrants: Glycolys ${ }^{\circledR}$ and Kollidon CL® often used in direct compression.

\section{Tabletability}

As observed in Fig. $6 a-b$, the addition of $5 \%$ alginic acid to the targeted fillers has slightly influenced the hardness of the tablets.

While the addition of acid alginic caused a reduction in hardness of tablets obtained from the formulation (MCC/ AA), a slight increase in hardness was observed for (lactose/ AA) formulation compared to those obtained from pure diluents (lactose, MCC).

As alginic acid was found to be a brittle material possessing certain elastic properties, its addition to MCC caused a decrease in tablet hardness because of the occurrence of an elastic recovery. That weakens the binding

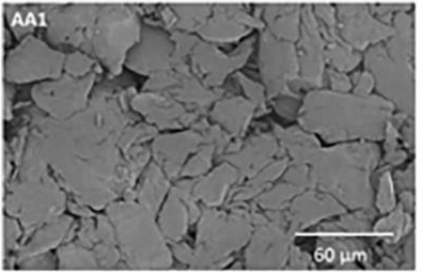

between particles, and as a result, less hard tablets were produced.

In contrast, the addition of alginic acid has improved the hardness of lactose tablets since alginic acid has less brittle behavior under compaction than lactose. Hence, their combination favors bonding because new surfaces are produced and consequently, an increase in contact area between

particles occurs during compression (39). In addition, the possibility of hydrogen bonds formation between particles of the two excipients improves the cohesion and gives harder tablets.

In general, the difference in tabletability between the two batches of alginic acid is negligible since they are present at a low content (5\%) in the formulations. Only, when they were mixed with MCC, the decrease in tablets hardness was more pronounced in the presence of AA2. This is obvious as this last one was found to be more elastic than AA1 in previous results.

\section{Disintegration Time}

The disintegration of the formulated tablets was largely influenced by the addition of $5 \%$ alginic acid as illustrated in Fig. $6 \mathrm{c}-\mathrm{d}$.

From a general point of view, no significant difference in the disintegration time was observed between the two batches when used at $5 \%$ in the formulated tablets despite the difference in their swelling behavior. Hence, the swelling force has no correlation with the disintegration time obtained. Similar observations were obtained by a previous

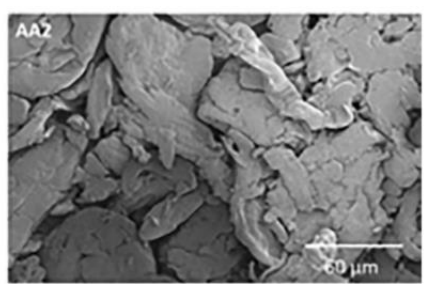

Fig. 4. SEM images of the tablet surface of AA1 and AA2 

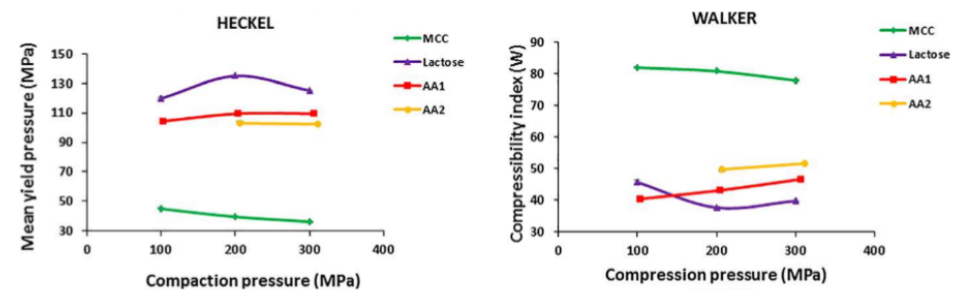

Fig. 5. Heckel and Walker plots of lactose, MCC, AA1, and AA2

comparative study of different alginic acids obtained by different drying methods (12). It was found that the disintegration time is not correlated to the swelling force but that it is mainly related to the water uptake kinetics.

In the formulation with MCC, alginic acid exhibited a rapid disintegration by the weakening of the tablets structure and by the creation of capillary pores. The combination of these two phenomena allows the water to enter the tablet matrix and then to break the hydrogen bonding between adjacent bundles of AA/MCC particles (40).

Tablets made from AA/lactose formulation were disintegrated faster than pure lactose tablets. This can be explained by a potential synergistically action between the alginic acid which possess the ability to absorb water (wicking action) and the rapid dissolution of crystalline lactose. Lactose has been shown to disintegrate very quickly in water

as a result of rapid liquid uptake and fast release of the bonds (41). Furthermore, the swelling of alginic acid could nullify the effect of the viscous barrier formed by lactose after dissolution, which slows down the water penetration, as observed when lactose is mixed with starch (42). The viscous resistance to water penetration disappears as the result of tablet collapse and a severe explosive disintegration occurs.

According to these results, it seems that alginic acid has disintegrating properties that are interesting and close to those of the main commercial superdisintegrants used: Glycolys ${ }^{\circledR}$ and Kollidon CL $®$. For this, the subsequent work will be based on the optimization of the properties of this excipient in order to improve its functionality in disintegration and direct compression.

\section{CONCLUSION}

The compaction and the disintegration behavior of two different batches of alginic acid were investigated after a complete physicochemical characterization. The two batches showed different tableting properties that seem to be mostly correlated to the difference on their molecular weights since they possess close uronic acid compositions. Alginic acid with the lowest molecular weight (AA1) exhibited the highest tablet's strength and presented the lowest elastic recovery after decompression. On the other hand, no difference was observed between the two batches regarding disintegration time despite the difference found in their swelling force. This

suggests that alginic acid promotes disintegration mainly by capillary action and very weakly by swelling. These results indicate that the molecular weight of alginic acid has an important effect on the tablet's strength as for the majority of natural polymers (MCC, chitosan) where the molecular weight visibly affects the mechanical properties and the deformation of the powder in compression. Therefore, a determination of the molecular weight seems to be indispensable for obtaining AA's tablets with reproducible strength. It was also noted that alginic acid possesses interesting tableting properties. Therefore, it must be better exploited not only as disintegrant but also as potential filler/binder. Finally, an
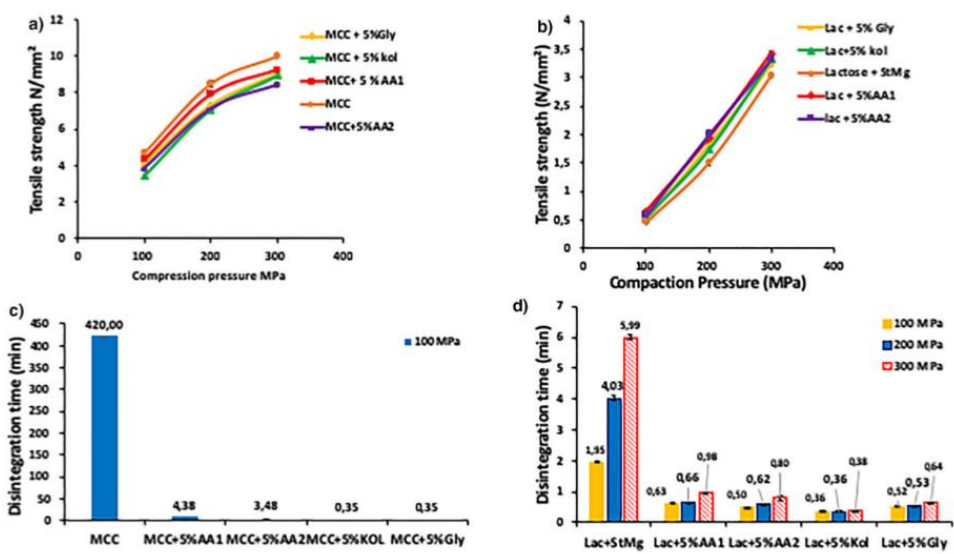

Fig. 6. Curves of tensile strength as function of compaction pressure (a, b) and in vitro disintegration time $(\mathbf{c}, \mathbf{d})$ for different formulations tested with $5 \%$ of disintegrant 
optimization of its powder rheology seems to be essential in future work in order to use it as a multifunctional excipient in direct compression.

\section{ACKNOWLEDGMENTS}

The authors would like to thank the electronic and analytical microscopy platform and the laboratory of physical measurements of the University of Montpellier for their contribution to this work.

\section{FUNDING INFORMATION}

This work was supported by the funding program from the Algerian Ministry of High Education and Scientific Research through the funding of the $\mathrm{PhD}$ of Rihab BENABBAS.

\section{REFERENCES}

1. Goh $\mathrm{CH}$, Heng PWS, Chan LW. Alginates as a useful natural polymer for microencapsulation and therapeutic applications. Carbohydr Polym. 2012;88:1-12.

2. Draget K, Skjakbrak G, Smidsrod O. Alginic acid gels: the effect of alginate chemical composition and molecular weight. Carbohydr Polym. 1994;25:31-8.

3. Skjak-Bræk G, Grasdalen H, Larsen B. Monomer sequence and acetylation pattern in some bacterial alginates. Carbohydr Res. 1986:154:239-50.

4. Gombotz WR, Wee SF. Protein release from alginate matrices. Adv Drug Deliv Rev. 1998;19.

5. Tønnesen HH, Karlsen J. Alginate in drug delivery systems. Drug Dev Ind Pharm. 2002;28:621-30.

6. Holte $\varnothing$, Ons $\varnothing$ yen E, Myrvold R, Karlsen J. Sustained release of water-soluble drug from directly compressed alginate tablets. Eur J Pharm Sci. 2003;20:403-7.

7. Schmid W, Picker-Freyer KM. Tableting and tablet properties of alginates: characterisation and potential for soft tableting. Eur J Pharm Biopharm. 2009;72:165-72.

8. Mandal S, Basu SK, Sa B. Sustained release of a water-soluble drug from alginate matrix tablets prepared by wet granulation method. AAPS PharmSciTech. 2009;10:1348-56.

9. Sriamornsak P, Thirawong N, Korkerd K. Swelling, erosion and release behavior of alginate-based matrix tablets. Eur J Pharm Biopharm. 2007;66:435-50

10. Liew CV, Chan LW, Ching AL, Heng PWS. Evaluation of sodium alginate as drug release modifier in matrix tablets. Int $\mathrm{J}$ Pharm. 2006:309:25-37.

11. Kornblum SS, Stoopak SB. A new tablet disintegrating agent: cross-linked Polyvinylpyrrolidone. J Pharm Sci. 1973;62:43-9.

12. Soulairol I, Sanchez-Ballester NM, Aubert A, Tarlier N, Bataille B, Quignard F, et al. Evaluation of the super disintegrant functionnalities of alginic acid and calcium alginate for the design of orodispersible mini tablets. Carbohydr Polym. 2018:197:576-85.

13. Berry H, Ridout CW. The preparation of compressed tablets: Part III-a study of the value of potato starch and alginic acid as

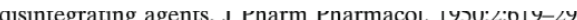

14. Mohanachandran PS, Sindhumol PG, Kiran TS. Superdisintegrants:an overview. Int J Pharm Sci Rev Res. 2011;6:5.

15. European Pharmacopeia. Alginic acid (monograph 0591). 2018a; p. 1781-2.

40. Bala R, Khanna S, Pawar P. Polymers in fast disintegration tablets - a review. Asian J Pharm Clin Res. 2012;5:8-14.

41. Vromans H, Bolhuis GK, Lerk CF, Kussendrager KD. Studies on tableting properties of lactose. VIII. The effect of variations in primary particle size, percentage of amorphous lactose and addition of a disintegrant on the disintegration of spray-dried lactose tablets. Int J Pharm. 1987;39:201-6.
16. Belalia F, Djelali N-E. Rheological properties of sodium alginates solutions. Rev Romaine Chim. 2014;59(2):135-45.

17. Martinsen A, Skjak-Bræk G, Smidsrod O, Zanetti F. Comparison of different methods for determination of molecular weigh and molecular weight distribution of alginates. Carbohydr Res. 1991;15:171-93.

18. Mackie W, Noy R, Sellen DB. Solution properties of sodium alginate. Biopolymers Biopolymers. 1980;19:1839-60.

19. Grasdalen H, Larsen B, Smidsrod O. A P.M.R. study of the composition and sequence of uronate residues in alginates. Carbohydr Res. 1979;68:23-31.

20. Sun $\mathrm{C}(\mathbf{C})$. True density of microcrystalline cellulose. J Pharm Sci. 2005;94:2132-4.

21. European Pharmacopeia. Bulk density and tapped density of powders (monograph 2.9.34); 2018b; p. 384-7.

22. Chaheen M, Soulairol I, Bataille B, Yassine A, Belamie E, Sharkawi T. Chitin's functionality as a novel disintegrant: benchmarking against commonly used disintegrants in different physicochemical environments. J Pharm Sci. 2017;106:1839-48.

23. Hersay JA, Rees JE. Deformation of particles during briquetting. Nat Phys Sci. 1971;230:96.

24. Tarlier N, Soulairol I, Bataille B, Baylac G, Ravel P, Nofrerias I, et al. Compaction behavior and deformation mechanism of directly compressible textured mannitol in a rotary tablet press simulator. Int J Pharm. 2015;495:410-9.

25. European Pharmacopeia. Disintegration of tablets and capsules (monograph 2.9.1) 9th ed, European directorate for the quality of Medicines \& HealthCare. Strasbourg: Council of Europe 2018c; p. 323-5.

26. Cheong M, Zhitomirsky I. Electrodeposition of alginic acid and

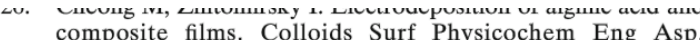
2008;328:73-8.

27. Ikeda A, Takemura A, Ono H. Preparation of low-molecular weight alginic acid by acid hydrolysis. Carbohydr Polym. 2000;42:421-5.

28. Orr SFD. Infra-red spectroscopic studies of some polysaccharides. Biochim Biophys Acta. 1954;14:173-81.

29. Soares JP, Santos JE, Chierice GO, Cavalheiro ETG. Thermal behavior of alginic acid and its sodium salt. Eclética Quím. 2004;29:57-64.

30. DeRamos CM, Irwin AE, Nauss JL, Stout BE. 13C NMR and molecular modeling studies of alginic acid binding with alkaline earth and lanthanide metal ions. Inorganica Chim Acta. 1997;256:69-75.

31. Anshuman S. Introduction to plastic engineering: polymerization. Plastic Design Library; 2018.

32. Kaerger JS, Edge S, Price R. Influence of particle size and shape on flowability and compactibility of binary mixtures of paracetamol and microcrystalline cellulose. Eur J Pharm Sci. 2004;22:173-9.

33. Augsburger LL, Hoag SW. Pharmaceutical dosage forms. Tablets. 3rd ed. New York: Informa Healthcare USA; 2008.

34. Ramos PE, Silva P, Alario MM, Pastrana LM, Teixeira JA, Cerqueira MA, et al. Effect of alginate molecular weight and M/ $\mathrm{G}$ ratio in beads properties foreseeing the protection of probiotics. Food Hydrocoll. 2018;77:8-16.

35. Tye CK, Sun C(C), Amidon GE. Evaluation of the effects of tableting speed on the relationships between compaction pressure, tablet tensile strength, and tablet solid fraction. J Pharm Sci. 2005;94:465-72.

36. Picker-Freyer KM, Brink D. Evaluation of powder and tableting properties of chitosan. AAPS PharmSciTech 2006;7(3):E152.

37. Kokil SN, Patil PR, Mahadik KR, Paradkar AR. Effect of molecular weight of hydrolyzed gelatin on its binding properties

in tablets: a technical note. AAPיS PharmSciTech. 20̄04;5:38-42. 38. Shlieout G, Arnold K, Müller G. Powder and mechanica properties of microcrystalline cellulose with different degrees of polymerization. AAPS PharmSciTech. 2002;3:45-54.

39. Nachaegari SK, Bansal AK. Coprocessed excipients for solid dosage forms. Pharm Technol 2004;52-64.
42. Ganderton D, Fraser DR. Some observations of the penetration and disruption of tablets by water. J Pharm Pharmacol 1970;22:95S-103S. 